\title{
Role of ultrasonography with color-Doppler in the emergency diagnosis of acute penile fracture: a case report.
}

\author{
Ramazan Buyukkaya $^{1}$, Ayla Buyukkaya², Beyhan Ozturk¹, Ali Kayıç̧ı ${ }^{3}$ Ömer Yazgan²
}

${ }^{1}$ Düzce University, School of Medicine, Department of Radiology, ${ }^{2}$ Duzce Atatürk Government Hospital, Department of Radiology, ${ }^{3}$ Düzce University, School of Medicine, Department of Urology, Turkey

\section{Abstract}

Penile fracture is the rupture of tunica albuginea, typically resulting from blunt trauma, intercourse, or penile manipulation. Diagnosis is made clinically. Ultrasound is not used frequently in diagnosis of penile fracture but it provides a fast, noninvasive alternative to more often used MRI and cavernography. We aimed to present diagnostic ultrasound and color Doppler images of a patient with acute penile fracture in conjunction with literature.

Keywords: penile fracture, ultrasound, color Doppler

\section{Introduction}

Penile fracture is the rupture of one or both of the tunica albuginea, the fibrous coverings that envelope the corpora cavernosa, in the erect penis [1]. Since during erection thick tunica albuginea becomes thin and fracturable, penile fracture usually occurs during sexual intercourse or masturbation. Rarely is it caused by rapid blunt force onto erect penis following a fall from bed or during a fight [2]. Penile rupture can usually be diagnosed based solely on history and physical examination findings; however, in equivocal cases, radiographic examinations should be performed to confirm the diagnosis as well as to determine the localization of the tunical rupture [3]. In the diagnosis of penile fracture, an urologic emergency, ultrasonography is an easy-accessible and practical method that confirms the diagnosis and evaluates the extent of injury in the tunica. The purpose of this paper

Received 09.09.2013 Accepted 11.10.2013

Med Ultrason

2014, Vol. 16, No 1, 67-69

Corresponding author: Ramazan Büyükkaya, MD

Düzce University, School of Medicine,

Department of Radiology.

81000 Düzce, Turkey

Phone: +90 3805421390

E-mail: rbuyukkaya@gmail.com was to present the ultrasound and Doppler findings in a patient with penile rupture and to discuss the case in the light of pertinent literature.

\section{Case report}

A 32-year-old patient was admitted complaining of pain, swelling, and bruising following blunt trauma. On physical examination, the penis was swollen and ecchymotic. The hematoma deviated the penis away from the side of corporal injury. Sonographic examination revealed a $13 \times 2-\mathrm{mm}$ longitudinal tear in the tunica albuginea in the proximal third of the right penile shaft. Adjacent to the tunical defect, there was an intracavernous hematoma of $16 \times 9 \mathrm{~mm}$ and another extratunical hematoma extending peripherally (fig 1). There was no color Doppler signal in the intra- and extracavernous hematomas (fig 2). The corpus spongiosum and penile vascular structures were normal.

\section{Discussion}

Penile fracture is described as the rupture of the tunica albuginea and/or tunica spongiosum in the erect penis caused by rapid blunt force. Penile fracture is an uncommon injury, but is a medical emergency [4]. Among 


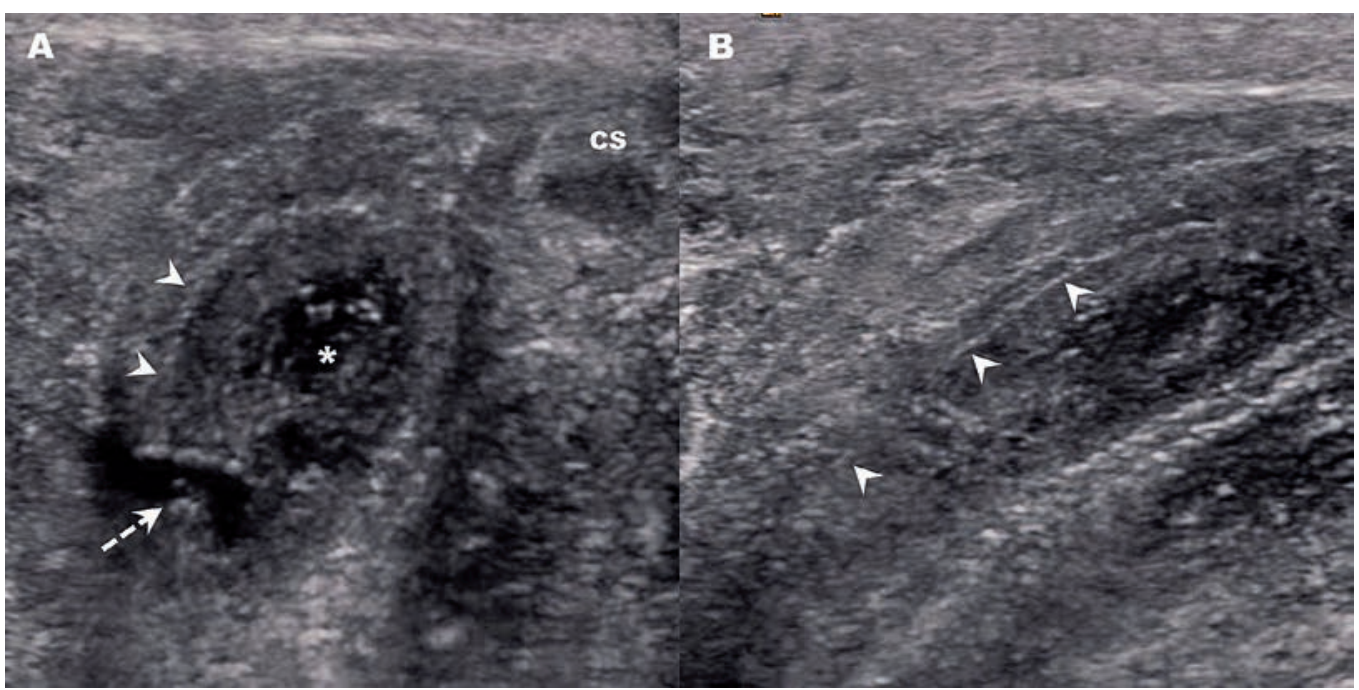

Fig 1. Longitudinal tear of the tunica albuginea in the proximal third of the right penile shaft. (A) Transverse sonogram shows the 2-mm tear (arrows). The sign $\left({ }^{*}\right)$ point to the intracavernous hematoma. (B) Appears as an interruption of the tunica albuginea (arrowheads).

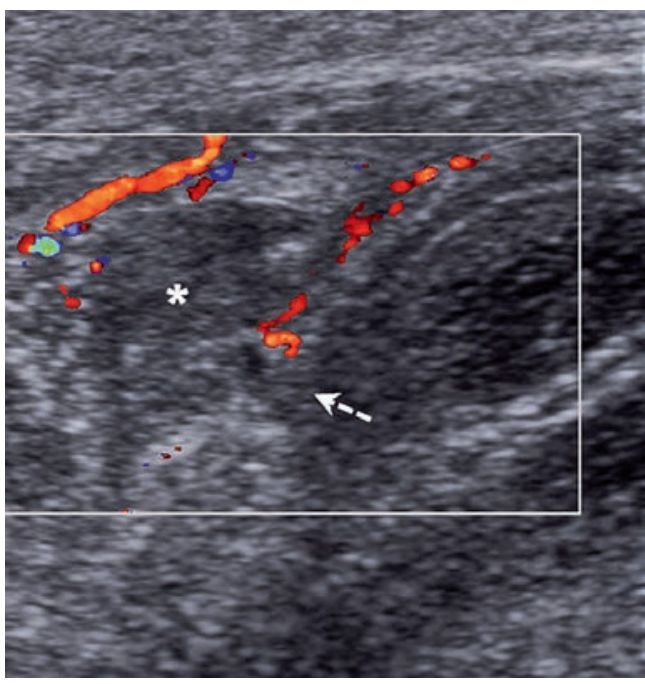

Fig 2. Color Doppler sonogram shows a 2-mm tunical irregularity in the proximal third of the right penile shaft (arrows) and a $24 \times 11 \mathrm{~mm}$ heterogeneous hypoechoic extratunical hematoma $(*)$ region with a small amount of peripheral vascularity (double arrows).

175,000 patients referring to the hospital, only one patient presented with the history of blunt penile trauma [5]. The erection changes the flaccid penis into a vulnerable rigid organ, where the $22 \mathrm{~mm}$-thick tunica albuginea becomes very thin $(0.5-2.5 \mathrm{~mm})$ and prone to fracture. During this time a compressive blunt trauma to or abrupt bending of the penis causes a sudden increase in intracavernonus pressure which ultimately results in penile fracture $[6,7]$.
The first document on penile fracture was written by Abul Kasım, an Arabian physician living in Cordoba, south Spain, approximately 1000 years ago. The first case reported in detail was by Malis in 1925. The etiology depends on the prevalent mechanism of penile injury in different countries [8]. It is most commonly associated with sexual intercourse and occurs when the erect penis slips from the vagina striking the partner's extra-vaginal sites (perineum, symphysis) and is rarely associated with abrupt lateral bending of the penis during masturbation. The other causes are more uncommon $[3,7]$. In the western world like America and Europe penile fracture is most commonly associated with sexual intercourse whereas in the Middle-East, Mediterranean and Far-East countries with manual correction of the penis, masturbation or rolling over in bed [6].

The diagnosis of penile fracture is easy, based on history and clinical findings, as accepted by many authors. However, additional diagnostic imaging modalities such as cavernography, urethrography, ultrasonography, Doppler ultrasonography, MRI, and angiography can be used for diagnosis [3]. In equivocal cases ultrasonography and Doppler ultrasonography can confirm the diagnosis.

There is usually a history of a blunt trauma in the history of patients. The patients present by reporting first an audible "popping" sound followed by pain, hematoma formation, and rapid detumescence (loss of swelling) [9]. Following injury, as long as Buck's fascia remains intact, hematoma and ecchymosis are limited to the penis. If Buck's fascia is torn, the hematoma may extend through the fascias to the scrotum and pubic region [10]. Often, 
the tunical laceration is unilateral, transverse, not surpassing half of corpus cavernosum, and distally localized [9]. There may be an associated partial or complete urethral rupture or deep dorsal vein injury. The associated urethral injury is observed in $38 \%$ of penile fractures in the western world such as America and Europe where high-energy injuries are prevalent and in only $3 \%$ in the eastern countries where, in contrast, low-energy injuries are prevalent [6].

Although in physical examination the corporeal defect at the fracture site is often palpable, swelling and hematoma may hinder palpation. Blood at the meatus and a partial or complete inability to void are the signs of urethral injury. Our case showed no clinical signs of urethral injury and no pathology in the corpus spongiosum in sonographic examination. If Buck's fascia is torn, the extravasation of blood and/or urine may extend to the scrotum, suprapubic region, and perineum, giving rise to the "butterfly" pattern of ecchymosis [11]. Following injury, if Buck's fascia remains intact, the extravasated blood entering between the skin and fascial components of tunica albuginea causes a hematoma resulting in the characteristic "eggplant deformity", which has a high diagnostic significance [12]. Our case showed no such signs reported in the literature.

Ultrasonography is not routinely used in the diagnosis of penile fracture. It is a noninvasive method giving results faster than cavernography and MRI. In ultrasonography tunica albuginea is easily depicted as a hyperecogenic linear line. The presence of a defect and hematoma in the hyperecogenic line may indicate penile fracture; in case of small defects, increased vascularity is observed. The evaluation of ultrasonographic dimensions can be helpful in determining intra- and extra-tunical hematomas [13]. The drawback of the method is that it should be performed only by the experienced. In the literature the studies on the diagnosis of penile fracture by using Doppler ultrasound, reported as a valuable diagnostic tool, are limited in number [14]. As already seen in our case, we think that ultrasonography should be best reserved for cases where the diagnosis is unclear or the history is not typical. Magnetic resonance imaging has been advocated, and though this modality can be useful in assessing penile fracture more in detail, its restricted availability and high cost limit its use.

Studies comparing surgical versus conservative treatment in penile fracture favour surgical treatment. Immediate surgical intervention has been associated with a reduced risk of permanent penile curvature, shorter duration of hospital stay, and reduced return time to normal erectile function [15]. Following the fracture, the extensive hematoma and/or urinary extravasation developed may negatively effect the wound healing and may also cause fibrosis in the cavernous tissue leading to penile deformity in the course of time. In view of these complications, conservative therapy is not recommended for each patient, but should be restricted to patients refusing surgery or to uncomplicated cases [15].

As experienced in our case, in equivocal cases ultrasonography and Doppler ultrasonography can confirm the diagnosis. Sonography can depict the site of tunical tear, thus helping the surgeon to determine the dimensions of the defect and associated complications.

In conclusion, we think that sonographic imaging is required in the evaluation of patients with penile fracture.

\section{References}

1. Cecchi M, Pagni GL, Ippolito C, Summonti D, Sepich CA, Fiorentini L. Fracture of the penis; description of a case. Arch Ital Ural Androl 1997; 69: 137-139.

2. Schrama J, Skjetne O, Vada K. Penis fracture. Tidsskr Nor Laegeforen1998; 118: 2017-2018.

3. Karadeniz T, Topsakal M, Ariman A, Erton H, Basak D. Penile fracture: differential diagnosis, management and outcome. Br J Urol 1996; 77: 279-281.

4. Tahmaz L, Kilciler M, Gökalp A, Soydan H, Dayanç M, Peker AFk. Penis Fraktürlü 14 Olguda Cerrahi Tedavi Sonuçlarımız. Türk Üroloji Dergisi 2000; 26: 310-312.

5. Aksoy Y, Özbey İ, Biçgi O, Polat Ö, Demirel. A, Okyar G. Penis Fraktürü ve Tedavi Sonuçları. Ulusal Travma Dergisi 1999; 5: 93-95.

6. Zargooshi J. Penile fracture in Kermanshah, Iran: report of 172 cases. J Urol 2000; 164: 364-366.

7. Asgari MA, Hossieni SY, Safarinejad MR, Samadzadeh B, Bardideh AR. Penile fracture: evaluation, therapeutic approaches and long term results. J Urol 1996;155:148-149.

8. Eke N. Fracture of the penis. Br J Surg 2002; 89: 555-565.

9. Muentener M, Suter S, Haurı D, Sulser T. Long-term experience with surgical and conservative treatment of penile fracture. J Urol 2004; 172: 576-579.

10. El-Taher AM, Aboul-Ella HA, Sayed MA, Gaafar AA. Management of penile fracture. J Trauma 2004; 56: 11381140.

11. Gottenger EE, Wagner JR: Penile fracture with complete urethral disruption. J Trauma 2000; 49: 339-341.

12. Mydlo JH, Hayyeri M, Macchia RJ. Urethrography and cavernosography imaging in a small series of penile fractures: a comparison with surgical findings. Urology 1998; 51: 616-619.

13. Nomura JT, Sierzenski PR. Ultrasound diagnosis of penile fracture. J Emerg Med 2010; 38: 362-365.

14. Kervancioglu S, Ozkur A, Bayram M. Color Doppler sonographic findings in penile fracture. J Clin Ultrasound 2005; 33: 38-42.

15. Beysel M, Tekin A, Gürdal M, Yücebaş E, Şengör F. Evaluation and treatment of penile fractures: accuracy of clinical diagnosis and the value of corpus cavernosography. Urology 2002; 60: 492-496. 